\title{
Engagement Matters: Student Perceptions on the Importance of Engagement Strategies in the Online Learning Environment
}

\author{
Florence Martin \\ University of North Carolina Charlotte \\ Doris U. Bolliger \\ University of Wyoming
}

\begin{abstract}
Student engagement increases student satisfaction, enhances student motivation to learn, reduces the sense of isolation, and improves student performance in online courses. This survey-based research study examines student perception on various engagement strategies used in online courses based on Moore's interaction framework. One hundred and fifty-five students completed a 38-item survey on learner-to-learner, learner-to-instructor, and learner-to-content engagement strategies. Learner-to-instructor engagement strategies seemed to be most valued among the three categories. Icebreaker/introduction discussions and working collaboratively using online communication tools were rated the most beneficial engagement strategies in the learner-to-learner category, whereas sending regular announcements or email reminders and providing grading rubrics for all assignments were rated most beneficial in learner-to-instructor category. In the learner-content category, students mentioned working on real-world projects and having discussions with structured or guiding questions were the most beneficial. This study also analyzed the effect of age, gender, and years of online learning experience differences on students' perception of engagement strategies. The results of the study have implications for online instructors, instructional designers, and administrators who wish to enhance engagement in the online courses.
\end{abstract}

Keywords: online learning, asynchronous, engagement, student perception

Martin, F. \& Bolliger, D.U. (2018). Engagement matters: Student perceptions on the importance of engagement strategies in the online learning environment. Online Learning 22(1), 205222. doi:10.24059/olj.v22i1.1092

\section{Engagement Matters: Student Perceptions on the Importance of Engagement Strategies in the Online Learning Environment}

Engagement is crucial to student learning and satisfaction in online courses. The definition of engagement has been extensively explored in distance and online learning literature for decades. Student engagement is defined as "the student's psychological investment in and effort directed 
toward learning, understanding, or mastering the knowledge, skills, or crafts that academic work is intended to promote" (Newmann, Wehlage, \& Lamborn, 1992, p. 12). Student engagement in online learning is very important because online learners seem to have fewer opportunities to be engaged with the institution. Hence, it is essential to create multiple opportunities for student engagement in the online environment. The need for engagement has resulted in the development of guidelines for designing effective online courses (Roblyer \& Ekhaml, 2000). Engagement strategies are aimed at providing positive learner experiences including active learning opportunities, such as participating in collaborative group work, having students facilitate presentations and discussions, sharing resources actively, creating course assignments with handson components, and integrating case studies and reflections. Banna, Lin, Stewart, and Fialkowski (2015) stress that engagement is the key solution to the issue of learner isolation, dropout, retention, and graduation rate in online learning. Meyer (2014), Banna et al. (2015), and Britt (2015) assert the importance of student engagement to online learning because they believe student engagement can be shown as evidence of students' considerable effort required for their cognitive development and their given ability to create their own knowledge, leading to a high level of student success.

According to Banna et al. (2015), if content played a central focus in the past, engagement plays an important role in stimulating online learning today. To boost student engagement, three basic engagement techniques of online learning have been identified: student-content, studentinstructor, and student-student (Bernard et al., 2009). Lear, Ansorge, and Steckelberg (2010) say that interactions with content, peers, and instructors help online learners become active and more engaged in their courses. Interactivity and sense of community result in high-quality instruction and more effective learning outcomes.

\section{Framework}

\section{Review of Related Literature}

Interaction and engagement are closely related and even used interchangeably. Student engagement is developed through interaction (Anderson, 2003), and fostering interaction is important in online learning. On reviewing research in the higher education context, Chickering and Gamson (1987) proposed a framework to ensure students' engagement: "Seven Principles for Good Practice in Undergraduate Education." The seven principles identified in this framework list that students are more engaged when the instruction (1) increases the contact between student and faculty, (2) provides opportunities for students to work in cooperation, (3) encourages students to use active learning strategies, (4) provides timely feedback on students' academic progression, (5) requires students to spend quality time on academic tasks, (6) establishes high standards for acceptable academic work, and (7) addresses different learner needs in the learning process. Several of these seven principles apply to the online learning environment even though they were proposed for the face-to-face classroom.

Moore (1993) identified three types of interaction inherent in effective online courses: (1) learner-to-learner interaction, (2) learner-to-instructor interaction, and (3) learner-to-content interaction. This was used as the guiding framework for this study (see Figure 1). Lear et al. (2010) found that interactions with peers, instructors, and content help online learners become active and more engaged in their courses. 


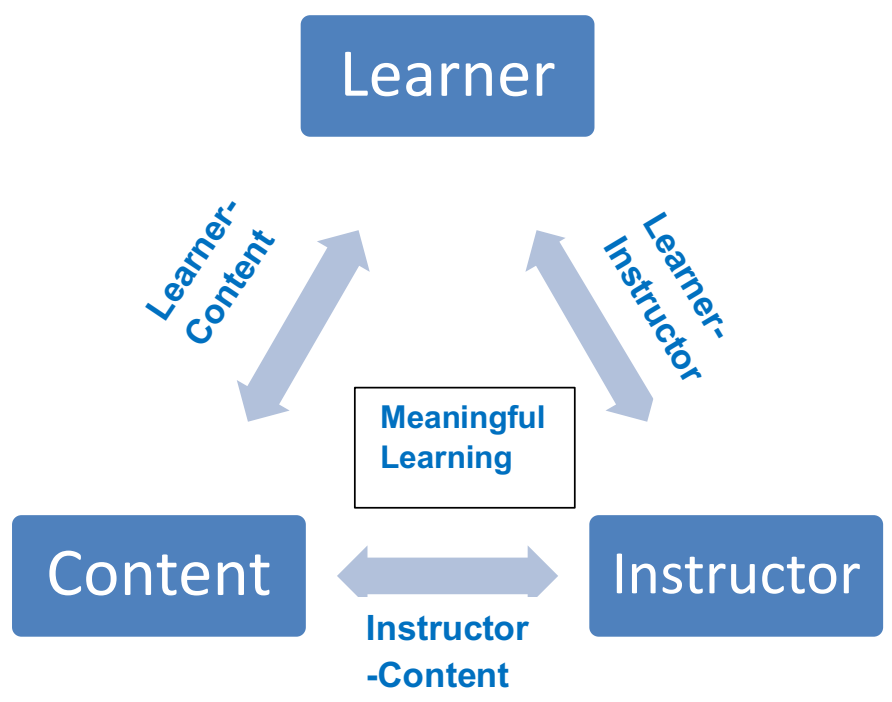

Figure 1. Types of interactions, based on Moore's framework.

Lear et al. (2010) depicted the distance education online environment interactivity/community-process model (see Figure 2) showing the relationship between interactivity, sense of community, and the engaged learner. They found interactivity and sense of community correlated to learner engagement.

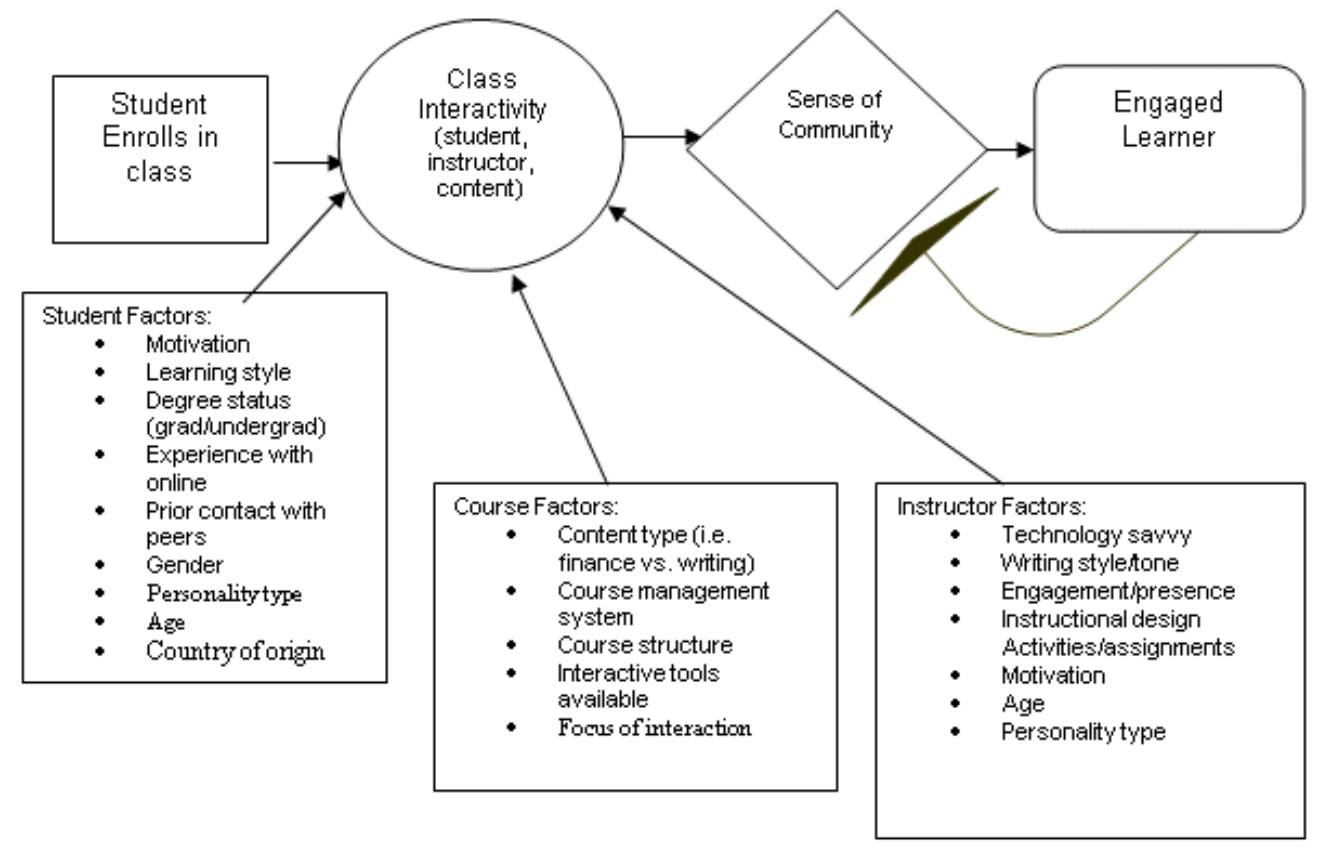

Figure 2. Distance education online environment interactivity/community-process model.

From "Interactivity/Community Process Model for the Online Education Environment," by J. L. Lear, C. Ansorge, and A. Steckelberg, 2010, Journal of Online Learning and Teaching, 6, p. 74. Reprinted with permission. 


\section{Learner-to-Learner Engagement}

Learner-to-learner interaction is extremely valuable for online learning and leads to student engagement. To prevent online students from experiencing potential boredom and isolation in the learning environment, it is essential to build activities that enhance engagement. These activities assist students in feeling connected and can create a dynamic sense of community. Revere and Kovach (2011) and Banna et al. (2015) found that traditional technologies for engaged learning, such as discussion boards, chat sessions, blogs, wikis, group tasks, or peer assessment, have served well in promoting student-to-student interaction in online courses. The authors highly recommend the use of web-based applications, such as Twitter feeds, Google applications, or audio and video technology like Wimba Collaboration Suite, in order to improve engagement in online courses. Shea, Fredericksen, Pickett, Pelz, and Swan (2001), in a survey of 3,800 students, found that when a greater percentage of the course grade was based on discussions, students were more satisfied, and they thought they learned more. Learners thought that they had more interaction with their peers and instructor. Banna et al. (2015) suggest using videoconferencing or chatting in synchronous activities, and discussion boards in asynchronous activities; they enhance student-tostudent interaction. Utilization of social media in online courses provides an opportunity to enhance engagement through social interaction (Everson, Gundlach, \& Miller, 2013; Tess, 2013).

\section{Learner-to-Instructor Engagement}

Learner-to-instructor interaction leads to higher student engagement in online courses (Dixson, 2010; Gayton \& McEwen, 2007). The use of multiple student-instructor communication channels may be highly related to student engagement. It is recommended that online instructors pay special attention to student-instructor interactions because they may affect learning outcomes (Dixson, 2010; Gayton \& McEwen, 2007). The authors found rapport and collaboration between students and instructors in an interactive and cohesive environment, including group work and instructive feedback, are important for student engagement resulting in learning success. Students often contact instructors about assignments, course materials, and grades; but to be more effective, online instruction should include opportunities for students to interact with one another and instructors pertaining to what makes their learning meaningful. In addition, Gayton and McEwen (2007) stress that instructors' presence in online courses is required in terms of actively involving students in their courses; however, online instructors should be minimally active in discussions when online courses are purposefully designed so that the more students engage, the more meaningful learning outcomes will be. Dixson (2010) and King (2014) also agree that there must be cooperation and collaboration between students and instructors in online courses in order to increase online student engagement.

Research has found that rapport and collaboration between students and instructors in an interactive environment are important. King (2014) found that students rated thorough and timely instructor feedback on their work as most valuable so that they can make improvements in their learning process. Mini videos and screencasting are techniques to increase instructor visibility that have been believed to bring many pedagogical benefits. Dixson (2010) and King (2014) stress that consistent interaction with students at the individual and group levels help set academic expectations among students. Instructor assessment of student work and participation using stated grading policy, providing summative feedback, and posting grades within a specified time frame can be highly beneficial. Revere and Kovach (2011) and Robinson and Hullinger (2008) suggest the use of new but well-established technologies, such as discussion boards, chat sessions, blogs, wikis, group tasks, Twitter, Skype, YouTube, and Ning networks, to foster student engagement 
through course design and technology integration. These technologies are also used for effective social-networking activities in online active learning for increasing student engagement.

\section{Learner-to-Content Engagement}

Learner-to-content engagement is the process of intellectually interacting with the content, which can change a learner's understanding and perspectives (Moore, 1993). Abrami, Bernard, Bures, Borokhovski, and Tamim (2011) state that student-to-content interaction can occur while watching instructional videos, interacting with multimedia, and searching for information. Both synchronous and asynchronous delivery are seen as effective options that help online students in accessing content for critical interaction (Banna et al., 2015). Online instructors are advised to invest sufficient time searching for scholarly reading and interactive instructional materials and designing well-thought-out assessments for the purpose of encouraging student-to-content engagement (Abrami et al., 2011; Banna et al., 2015). Real-world application of projects that enhances subject mastery and critical thinking skills is one strategy related to fostering learner-tocontent engagement. It refers to authenticity of the course content shown through real-world examples (Britt, 2015). Revere and Kovach (2011) recommend making the content come alive using appropriate technology, which enhances student engagement. Online instructors should be critical in choosing material and content when they wish to engage students more in their courses. Online students should not merely be given a list of resources, but instead instructors should design authentic activities that provide opportunities to examine the tasks from different perspectives and that encourage students to wisely use relevant information in the process. Dixson (2010) reports that students found a variety of activities made them feel engaged, including course management system features, effective communication, and course facilitation strategies.

\section{Purpose of the Study}

The purpose of this study is to investigate the importance of engagement strategies to online learners. The following research questions guided the study:

1. Which strategies do students perceive to be important in enhancing learner-learner, learner-instructor, and learner-content engagement in the online environment?

2. Which strategies do students identify as most valuable and least valuable to engaging them in the online learning environment?

3. Are there differences in responses based on individual differences, such as gender, age, and experience with online courses?

\section{Setting, Sample, and Participants}

\section{Methodology}

The sample consisted of online students at eight universities across the United States. The researchers solicited the assistance of faculty members who taught in online graduate programs at these institutions in a variety of programs to invite enrolled students via electronic mailing lists to participate in the study. These universities were selected because they are diverse in geography and size (student enrollment numbers), and both teaching and research universities were included. A total of 155 participants completed the online survey.

Participants. Most participants were female (67.8\%), whereas 32.2\% were male. Their ages ranged from 20 to $67(M=39.6)$. Over half of them $(51.7 \%)$ were enrolled in a master's degree program. Other students identified themselves as doctoral $(35.2 \%)$, postdoctoral $(5.5 \%)$, 
postbachelor (4.1\%), and postmaster (2.1\%) students; $1.4 \%$ of participants were pursuing a graduate certificate. Most participants were studying in the discipline of education $(85.5 \%)$, whereas others were in health sciences $(8.9 \%)$, engineering $(2.8 \%)$, arts and sciences $(2.1 \%)$, and business $(0.7 \%)$. Participants reported they had completed anywhere from 0 to 100 online courses $(M=14.0)$.

\section{Data Collection}

Data were collected during the spring 2016 semester via an online survey instrument that was housed on a secure server at one of the institutions affiliated with the researchers. Faculty members were asked to forward the invitation to participate in the study to students enrolled in their online programs via email distribution lists. Prior to the data collection, approvals from all relevant institutional review boards were obtained. The invitation included a cover letter with information about the study and a link to the online survey. Participation was voluntary, and all responses were anonymous. After approximately two weeks, one reminder was sent to all students. Participants were able to register for the drawing of three $\$ 25.00$ gift cards.

\section{Instrument}

The instrument was developed by the researchers after conducting an extensive literature review on student engagement in higher education. Likert-type items were developed based on three types of interaction (Moore, 1993): student-to-student, student-to-instructor, and student-tocontent. The original instrument included a total of 47 questions: 36 Likert items, three open-ended questions, and eight demographic questions.

The instrument was reviewed by five members of an expert panel prior to the data collection. All participating experts had at least seven years of online teaching experience in higher education; two of them were also experts in research methods. They were provided with a copy of the instrument and instructions to review all questions, make changes, and add or delete relevant items.

The expert review resulted in the modification, addition, and deletion of several questions and a revised Likert scale. The final version of the instrument included 38 total questions: 29 Likert-type items ranging from 1 (very unimportant) to 5 (very important), three open-ended questions, and six demographic questions. The demographic questions included age and gender, current student status and number of online courses completed, and discipline and major. After the data collection phase, Cronbach's alpha coefficients were calculated to ensure the instrument's internal reliability. The instrument had an internal reliability coefficient of .87 , and the reliability for the three subscales were satisfactory: (a) learner-to-learner $(a=.74)$, (b) learner-to-instructor $(a=.73)$, and (c) learner-to-content $(a=.73)$.

\section{Data Analysis}

Because nine cases had one third of their data missing, they were deleted from the data set. The deletion of these cases left a total of 146 valid cases. Missing values were replaced with the series mean, and frequencies and descriptive statistics were generated. Three new variables were created based on the three types of interaction. Independent samples $t$-tests and a series of analyses of variance were run to ascertain differences in responses based on gender, age, and experience with online courses. Topic and analytical coding were used to analyze responses to the three openended questions (Flick, 2006; Richards, 2009). Responses were coded to detect and create categories, and emerging categories were sorted and compared in order to develop common themes. 


\section{Results}

\section{Importance of Student Engagement Strategies}

In general, participants thought that engagement strategies listed on the instrument were somewhat important. Possible total scale scores ranged from 29 to 145 (based on 29 items with a range of 1 to 5), and respondents' scores ranged from 84 to $145(M=113.74 ; S D=12.06)$. Their total mean scores ranged from 2.90 to $5.00(M=3.92 ; S D=0.42)$.

On the learner-to-learner subscale, over $80 \%$ of respondents agreed that Item $3(81.4 \%)$ was important or very important; this item had not only the highest mean score on this subscale (Table 1) but also the only mean score above 4.0 . Over $70 \%$ agreed that Item $8(78.1 \%)$ and Item $7(76.1 \%)$ were important or very important. More than $60 \%$ of students believed that Item 5 (69.7\%), Item 9 (66.9\%), and Item 4 (64.6\%) were important or very important.

\begin{tabular}{lll}
\multicolumn{1}{c}{ Item } & M & SD \\
\hline $\begin{array}{l}\text { 1. Students use a virtual lounge where they can meet informally to share } \\
\text { common interests. }\end{array}$ & 3.03 & 1.17 \\
2. Students complete an integrated profile on the learning management & 3.45 & 0.97 \\
system that is accessible in all courses. & & \\
$\begin{array}{l}\text { 3. Students introduce themselves using an icebreaker discussion. } \\
\text { 4. Students moderate discussions. }\end{array}$ & 4.08 & 0.93 \\
$\begin{array}{l}\text { 5. Students have choices in the selection of readings (articles, books) that } \\
\text { drive discussion group formation. }\end{array}$ & 3.55 & 0.93 \\
$\begin{array}{l}\text { 6. Students post audio and/or video files in threaded discussions instead of } \\
\text { only written responses. }\end{array}$ & 3.60 & 0.95 \\
$\begin{array}{l}\text { 7. Students interact with peers through student presentations } \\
\text { (asynchronously or synchronously). }\end{array}$ & 3.89 & 0.93 \\
$\begin{array}{l}\text { 8. Students work collaboratively using online communication tools to } \\
\text { complete case studies, projects, reports, etc. }\end{array}$ & 3.94 & 1.07 \\
$\begin{array}{l}\text { 9. Students peer-review classmates' work. } \\
\text { 10. Students are required to rate individual performance of team members on } \\
\text { projects. }\end{array}$ & 3.68 & 1.09 \\
\hline
\end{tabular}

Note: Scale ranging from 1 (very unimportant) to 5 (very important).

Table 1. Means and Standard Deviations for Items on the Learner-to-Learner Subscale

The majority of participants valued engagement strategies on the learner-to-instructor subscale. Item 12 had the highest mean score $(M=4.53 ; S D=0.67)$, with $94.4 \%$ of students agreeing that it is important or very important (Table 2), and $90.1 \%$ agreed with Item 19 . Over $80 \%$ of students agreed with Item $11(89.3 \%)$, Item $13(89.1 \%)$, and Item $15(87.5 \%)$. Only two items on this subscale received a mean score below 4.0. 
Student Perceptions on the Importance of Engagement Strategies in the Online Learning Environment

\begin{tabular}{lcc} 
Item & $\boldsymbol{M}$ & $\boldsymbol{S D}$ \\
\hline $\begin{array}{l}\text { 11. The instructor refers to students by name in discussion forums. } \\
\text { 12. The instructor sends/posts regular announcements or email reminders. }\end{array}$ & 4.13 & 0.87 \\
13. The instructor creates a forum for students to contact the instructor with & 4.53 & 0.67 \\
questions about the course. & 4.36 & 0.81 \\
$\begin{array}{l}\text { 14. The instructor creates a course orientation for students. } \\
\text { 15. The instructor posts a "due date checklist" at the end of each instructional unit. }\end{array}$ & 4.10 & 0.33 \\
$\begin{array}{l}\text { 16. The instructor creates short videos to increase instructor presence in the course. } \\
\text { 17. The instructor provides feedback using various modalities (e.g., text, audio, }\end{array}$ & 4.04 & 0.89 \\
$\begin{array}{l}\text { video, and visuals). } \\
\text { 18. The instructor provides students with an opportunity to reflect (e.g., via a }\end{array}$ & 3.67 \\
journal or surveys). & 0.88 \\
$\begin{array}{l}\text { 19. The instructor posts grading rubrics for all assignments. } \\
\text { 20. The instructor uses various features in synchronous sessions to interact with } \\
\text { students (e.g., polls, emoticons, whiteboard, text, or audio and video chat). }\end{array}$ & 4.41 & 0.99 \\
\hline
\end{tabular}

Note: Scale ranging from 1 (very unimportant) to 5 (very important).

Table 2. Means and Standard Deviations for Items on the Learner-to-Instructor Subscale

Over 90\% of respondents agreed that Item $24(95.2 \%)$ and Item 28 (92.4\%) were important or very important strategies to engage online students. Eighty-two percent of participants agreed that Item 22 was important to very important. Five items on this subscale had a mean score of 4.0 or above, and the item with the highest mean score was Item 28 (Table 3).

\begin{tabular}{lcc} 
Item & M & SD \\
\hline $\begin{array}{l}\text { 21. Students interact with content in more than one format (e.g., text, video, audio, } \\
\text { interactive games, or simulations). }\end{array}$ & 4.17 & 0.81 \\
$\begin{array}{l}\text { 22. Students use optional online resources to explore topics in more depth. } \\
\text { 23. Students experience live, synchronous web conferencing for class events } \\
\text { and/or guest talks. }\end{array}$ & 4.09 & 0.72 \\
$\begin{array}{l}\text { 24. Discussions are structured with guiding questions and/or prompts to deepen } \\
\text { their understanding of the content. }\end{array}$ & 4.40 & 1.06 \\
$\begin{array}{l}\text { 25. Students research an approved topic and present their findings in a delivery } \\
\text { method of their choice (e.g., discussions forum, chat, web conference, multimedia } \\
\text { presentation). }\end{array}$ & 3.97 & 0.66 \\
$\begin{array}{l}\text { 26. Students search for and select applicable materials (e.g., articles, books) based } \\
\text { on their interests. }\end{array}$ & 3.97 \\
$\begin{array}{l}\text { 27. Students have an opportunity to reflect on important elements of the course } \\
\text { (e.g., use of communication tools, their learning, team projects, and community). }\end{array}$ & 4.00 \\
$\begin{array}{l}\text { 28. Students work on realistic scenarios to apply content (e.g., case studies, } \\
\text { reports, research papers, presentations, client projects). }\end{array}$ & 4.40 \\
$\begin{array}{l}\text { 29. Students use self-tests to check their understanding of materials. } \\
\text { P. }\end{array}$ & 0.81 \\
\hline
\end{tabular}

Note: Scale ranging from 1 (very unimportant) to 5 (very important).

Table 3. Means and Standard Deviations for Items on the Learner-to-Content Subscale

Of the three subscales, the learner-to-instructor subscale had the highest mean score (Table 4). This indicates that, in general, online learners most valued strategies that provide interaction between learners and instructors. Strategies used to facilitate learner-to-learner interaction were thought of as least important. 
Student Perceptions on the Importance of Engagement Strategies in the Online Learning Environment

\begin{tabular}{lcc} 
Subscale & $\boldsymbol{M}$ & $\boldsymbol{S D}$ \\
\hline Learner-to-learner & 3.63 & 0.56 \\
Learner-to-instructor & 4.15 & 0.47 \\
Learner-to-content & 3.99 & 0.46 \\
\hline
\end{tabular}

Note: Scale ranging from 1 (very unimportant) to 5 (very important).

Table 4. Means and Standard Deviations for Subscales

\section{Most Valuable Strategies}

In response to the open-ended question "What is the most valuable strategy to engage you as an online learner?" a total of 232 strategies were mentioned by 138 respondents. Most comments pertained to the course itself $(n=146)$; other comments related to instructors $(n=68)$ and other students $(n=18)$ (Table 5). When students wrote about course materials, they liked video lectures and preferred to have content presented in a variety of formats (e.g., multimedia files). Several also appreciated the integration of videos, a well-prepared and well-structured course with relevant information and visuals, and a flexible approach.

Sixteen individuals thought online discussions were important in the engagement of online students. They felt that instructors should form small groups for discussions, post prompts that "encourage deep reflection" and "deeper understanding," and require students to participate. They also believed that multiple types of media should be used for responses of instructors and students. Finally, they felt that instructions, directions, and guidelines need to be clear. This category included clear course goals, criteria, expectations, and rubrics. A few students mentioned the need of a list with all due dates and checklists.

Thirteen students valued online, synchronous meetings (e.g., videoconferencing), online video chat or chat sessions as strategies to be engaged. Real-world, authentic, and meaningful assignments kept students engaged in their learning process. Ten participants appreciated being able to select topics for course assignments based on their interests and the opportunity to pick relevant readings. Two students liked the peer review of assignments.

\begin{tabular}{lrlllr} 
Course & \multicolumn{3}{c}{ Instructor } & Peers & \\
\hline Course materials & 48 & Feedback & 27 & Interaction & 16 \\
Discussions & 31 & Interaction/presence & 26 & Community & 2 \\
Instructions/guidelines & 28 & Support & 15 & & \\
Online meetings & 13 & & & \\
Assignments & 12 & & & \\
Choices & 10 & & & \\
Assessment & 4 & & & \\
\hline
\end{tabular}

Note: Response count. Respondents could mention multiple strategies.

Table 5. Categories of Valuable Engagement Strategies Reported by Respondents $(n=138)$ 
Instructor feedback was important to several students. Students expected timely feedback that was detailed, personalized, and constructive. A few liked to get video or audio feedback from the instructor. Interaction with the instructor and instructor presence were perceived as valuable by 14 and 12 respondents, respectively. Several learners needed their instructors to be responsive and supportive. They felt that instructors should respond to questions promptly and develop a relationship with the student. For example, one person wrote, "It is so encouraging to believe that the instructor is getting to know me as an individual, and is willing to connect with me personally." A person who encountered an unsupportive instructor wrote, "I felt that I was lonely in the desert .... Preparing a well-designed curricula without instructor support does not mean that students will be engaged as planned."

Online student interaction with peers was deemed valuable by several students. They liked to work on collaborative group activities or assignments and enjoyed when their peers were involved in the discussions. Two individuals mentioned the importance of community and the formation of relationships with other learners.

\section{Least Valuable Strategies}

When asked "What is the least valuable strategy to engage you as an online learner?" a total of 33 strategies were mentioned by 123 respondents. Thirty of these strategies regarded the course, whereas two strategies were specific to the instructor, and one regarded peers. The least valuable strategies reported were the integration of discussion forums $(n=28)$ followed by synchronous meetings, group, and peer review work $(n=18)$. For example, one student commented, "I simply find little value in reading and replying to a classmate's post. It's just not how I want to learn or interact in an online course. Even when discussions are set up following best practices, they simply feel like busy work consuming time." Regarding synchronous sessions, one student wrote, "I prefer to mull over deeper ideas and concepts before responding. I feel synchronous sessions are more of a social strategy. They lend well to becoming connected with the group, however, I do not gain much as far as learning and content." One student offered a perspective on the use of group projects. The person wrote, "We are all adults with busy lives - we take online classes so we don't have to cater to another person's schedule." While videos and synchronous meetings were listed by students as the most valuable strategies, they were also listed as least valuable strategies by other students.

\begin{tabular}{lclll} 
Course & & Instructor & Peers & \\
\hline Online discussions & 28 & Not seeing the instructor 3 & $\begin{array}{l}\text { Group projects and peer } \\
\text { review work }\end{array}$ & 18 \\
Synchronous meetings & 10 & Not receiving reminders & 1 & \\
Long text readings & 10 & & & \\
Videos & 8 & & & \\
Too much interaction & 6 & & & \\
Too many forms of media 6 & & & \\
\hline
\end{tabular}

Table 5. Categories of Least Valuable Engagement Strategies Reported by Respondents $(\mathrm{n}=123)$

\section{Other Beneficial Strategies}

In response to the open-ended question "What strategies not included in this questionnaire are beneficial to you as an online learner?" a total of 64 other strategies were mentioned by 90 
respondents. Fifty-seven strategies addressed the course, five strategies were specific to the instructor, and two strategies pertained to the peers. Real-world applications and video lectures were listed as beneficial by five respondents each, and being able to see the instructor was considered beneficial by four respondents. Timely feedback, networking with peers, and clear schedules/syllabi and expectations were rated as beneficial by three respondents each. One student commented, "I think meeting synchronously 2-3 times during a semester would be very beneficial. This could either be one-on-one with the instructor, or in small groups (via Skype or Google Hangouts). I think this would help create community and be a good way for instructors to checkin with students, get feedback, and get a pulse for how learners are doing."

\begin{tabular}{llllll} 
Course & & Instructor & \multicolumn{2}{c}{ Peers } \\
\hline Real-world applications & 5 & Seeing the instructor & 4 & Networking with peers & 3 \\
Video lectures & 5 & Timely feedback & 3 & & \\
\hline
\end{tabular}

Table 5. Categories of Beneficial Engagement Strategies Not Listed on the Questionnaire Reported by Respondents $(n=90)$

\section{Individual Differences}

Gender. An independent samples $t$-test was performed to evaluate whether females and males had statistically significant different responses to the items on the instrument and its subscales. The test was significant for Item $22, t(141)=2.03, p=.04$. For female students it was more important $(M$ $=4.18)$ to use additional online resources to explore topics in more depth than for male students $(M=$ $3.92)$.

Age. A series of one-way analysis of variance (ANOVA) tests were conducted to evaluate the differences in age and online course experiences. The ANOVA was significant for Item $12, F(3,134)$ $=4.31, p=.01$. Follow-up tests were conducted to evaluate pairwise differences among the means. Because the group sizes were unequal, the assumption was made that the variances among the groups were not homogenous; therefore, Dunnett's $C$ test was used. There was a significant difference in the mean scores between individuals $20-29$ years of age $(M=4.77, S D=0.42)$ and $40-49(M=4.21, S D$ $=0.89$ ). Students in the younger group thought it was more important for instructors to send or post regular announcements or email reminders than students in the older age group. The $95 \%$ confidence interval for the pairwise difference was 0.08 to 1.04 .

Level of experience. Respondents were sorted into three groups based on the successful completion of the number of online courses: 0-5 (low), 6-10 (medium), and 11 or more (high). The ANOVAs were significant for three items. There was a significant difference for Item $1, F(2,139)=$ $7.64, p=0.001$. The use of an informal virtual lounge was valued more by students with a low level of online course experience $(M=3.51, S D=1.12)$ than by students with a high level of experience $(M=$ 2.64, $S D=1.14)$.

There were statistically significant differences for Item $12, F(2,139)=8.29, p<.001$. Students in the low group $(M=4.80, S D=0.46)$ and medium group $(M=4.68, S D=0.62)$ thought that it was more important for an instructor to post announcements and send email messages regularly than students in the high group $(M=4.31, S D=0.74)$.

Results for Item 21 were also significant, $F(2,139)=3.15, p=.046$. Medium experience users $(M=4.39, S D=0.68)$ believed it was more important to interact with a variety of types of content than students in the high experience group $(M=3.99, S D=0.83)$. The $95 \%$ confidence intervals for the pairwise differences were 0.31 to 1.43 (Item 1 ); 0.21 to 0.78 , and 0.05 to 0.70 (Item 12); and 0.05 to 0.77 (Item 21). 


\section{Learner-to-Learner Engagement}

\section{Discussion}

In this study, quantitative findings show that students rated the icebreaker discussion as the most important engagement strategy. Baker (2011) recommends using icebreaker discussions where instructors can designate a rotating icebreaker role within each group. The findings of this study are consistent with findings of Reushle and Mitchell (2009), who also emphasize the importance of icebreaking activities in online learning settings to create and enhance a supportive and friendly atmosphere. Moreover, Watkins (2014) discusses icebreaker activities to create interactive, meaningful, and entertaining experiences for students.

Working collaboratively using online communication tools was rated second highest. In one of the open-ended questions, group work was rated as the least valuable strategy. This may explain why some students rated this item low; some students simply do not enjoy collaborating with peers. Beck (2010) states that students who are unable to ask questions directly and do not receive feedback from instructors depend more on other students and end up working collaboratively with each other. Lowyck and Pöysä (2001) mention that collaborative learning strengthens learners' analytical skills and enables them to further their knowledge.

Using a virtual lounge for discussions outside of class was rated as the least important strategy. Most participants in this study were graduate students and likely work full-time. Time may be a significant factor in whether a virtual lounge for discussions outside of class is useful for them. It may be that undergraduates or traditional master's level students who work part-time might find it more valuable. Also, some students may be communicating privately through email and other methods, as they might prefer their privacy. They may be getting enough socialization through the other course activities and, hence, they rated this as an unimportant strategy. This is inconsistent with previous findings from Harrell (2008), who praised the role of virtual lounges in building relationship among students. Graduate students may not have the time to participate in virtual lounges for discussion outside of class. Students can be enrolled in different courses but get together in lounges and can have formal or informal conversations. Nicholson (2002) also reported a positive impact on communication with the use of instant online messaging. It assisted in building a sense of community and provided opportunities for getting involved in communications pertaining to class or institutions.

\section{Learner-to-Instructor Engagement}

Sending regular announcements or email reminders was rated as a very important engagement strategy. Ko and Rossen (2010) also talk about the importance of sending email announcements in a course. They mention that emails allow course participants to have a record of course communications. Cuthrell and Lyon (2007) think that sending emails enables instructors to reach out to all students.

Providing grading rubrics for all assignments was rated as the next most important engagement strategy in this category. This finding is consistent with that of other researchers. For example, Gayton and McEwen (2007) believe that the use of rubrics is an effective technique for online assessment. They report that rubrics are valued by both students and instructors. Bali and Ramadan (2007) found positive outcomes with the use of rubrics in online assessment. According to the authors, rubrics allow better and more accurate evaluation of students. 
Providing students with an opportunity to reflect (e.g., via a journal or surveys) was rated as not important. This finding is inconsistent with prior findings. Other authors (Asterhan \& Schwarz, 2007; Martin \& Ertzberger, 2016), point out that reflection provides meaningful learning. They discuss the value of students sharing ideas, its influence on academic outcomes, and the development of critical thinking skills.

\section{Learner-to-Content Engagement}

Working on realistic scenarios (e.g., case studies, reports, research papers, presentations, client projects) was listed as the most beneficial strategy. Active learning strategies have been found to be an effective way to engage students and improve their academic outcomes (Felder \& Brent, 1996). Moreover, Stavredes and Herder (2014), discuss how important it is to choose and design course material and activities in a way that enables learners to explore, discover, and perfect their skills and gain knowledge.

Discussions that are structured and include guiding questions and/or prompts to deepen their understanding of the content was rated as another very important engagement strategy. Asynchronous online discussions are valuable in online learning. When they are guided by the instructor, they have the ability to develop students' cognitive skills and deepen their understanding of the content (Gilbert \& Dabbagh, 2005). Garrison and Cleveland-Innes (2005) point to the importance of quality contributions in online discussions.

In some course, students experience live, synchronous web conferencing sessions for class events and/or guest talks. However, in this study this was rated as not very important compared to other strategies. The finding from this study is inconsistent with prior findings. Ward, Peters, and Shelley (2010) found that courses with synchronous conferences were perceived to be of better quality by students compared to courses that were entirely asynchronous. Parker and Martin (2010) found that the integration of synchronous meetings in online courses can be beneficial to students because it increases student interaction. Students can develop their technology skills, and they have opportunities to interact with the instructor. One reason for the low rating of synchronous sessions in this study may be that respondents were enrolled in courses delivered mostly asynchronously.

\section{Other Strategies}

Our findings show that including a variety of course materials were very beneficial to online students. This is supported by Ko and Rossen (2010), who recommend using a variety of instructional material, including instructor generated resources, web resources, book chapters, multimedia resources, and instructional videos.

Interestingly, some students thought that online discussions were the least valuable strategy, which contradicted other results that showed discussions deepen students' understanding of content. However, respondents pointed out that structured discussions with guiding questions and/or prompts are more beneficial than unstructured discussions. Gašević, Adesope, Joksimović, and Kovanović (2015) found that high levels of cognitive presence in student-to-student discussions can be achieved by using externally facilitated regulation scaffolding and computersupported collaborative learning with role assignment.

Real-world application was a strategy that was rated as very important. Blumenfeld et al. (1991) stress the importance of project-based learning and the engagement of students in the investigation of authentic problems where motivation and thought are sustained. 
Though discussions were considered as the most valuable strategy in the quantitative data, they were considered as the least valuable strategy in the open-ended responses. This could have been due to the way the discussion forums were designed. When discussions are structured with guiding questions and/or prompts to deepen their understanding of the content, students consider them beneficial, according to the Likert-scale response in the Learner-to-content category.

\section{Limitations and Future Research}

Some methodological limitations need to be mentioned. First, the sample size is relatively small, and the sample was drawn from a limited number of universities. However, the list of universities included different classifications of universities and different geographical regions. Second, all data were self-reported due to the nature of the study. Third, the list of strategies is not an exhaustive list of all possible strategies that may be used to engage students in online classrooms. Last, respondents were solicited from multiple universities across the United States. The researchers had no control over the design and delivery of courses, programs, or strategies used by instructors. All of these elements impact the students' learning experience and influence their perceptions. Students whose instructors have not used some of these strategies may rate these strategies of lower importance. Readers should interpret the results with caution due to these limitations because results may have limited generalizability in different settings and contexts.

Other researchers could examine additional engagement strategies that are not included in the survey utilized to collect data in this study. Future research could focus on examining faculty perceptions of engagement strategies and compare differences between faculty and student perceptions. It would be worthwhile to investigate the perceptions of undergraduate students pertaining to engagement strategies and identify strategies that are more important to undergraduate versus graduate students.

\section{Conclusions}

This study confirms the importance of all three types of engagement strategies in online learning, especially learner-to-instructor engagement. This reinforces the belief that institutions need to design and deliver engaging learning experiences for students to succeed in online learning. Many of the strategies were highly rated by students and course designers, and instructors can use any of these strategies to enhance interaction in their online courses. The findings suggest that engagement can be enhanced both in the interactive design of online courses and also in the facilitation of the online courses. Instructor facilitation is crucial; hence, instructors need to have strategies for time management and engaging discourse.

The results from this study benefit (1) online instructors who are looking for various engagement strategies to implement in their online courses, (2) instructional designers who assist in the design and development of online courses, and (3) administrators who are looking at ways to increase engagement in online courses institution-wide. This study also adds to the research literature and assists other researchers in building on engagement strategies for online learning.

It is important to note that engagement strategies that support interactions with instructors were valued more than strategies that aimed at interactions with learning material and other learners. Instructor presence is very important to online learners. They want to know that someone "on the other end" is paying attention. Online learners want instructors who support, listen to, and communicate with them. As some of the participants mentioned, they appreciate frequent updates 
from their instructors and want to have an instructor who is not only responsive but supportive. Not surprisingly, students who participated in this study expected instructors to assist them in their learning and create meaningful leaning experiences, as evidenced by their assigning relatively high ratings for items pertaining to grading rubrics, checklists, forums, and student orientations.

The most important element in online learning is the instructor (Bolliger \& Martindale, 2004), although in some cases it is difficult to separate course material and instructional technology from the instructor. Instructors who wish to teach online or improve their online teaching effectiveness, instructional designers who want to build engaging online courses, and administrators who support staff and faculty working in successful online programs need to be aware of the importance of this fact. 


\section{References}

Abrami, P. C., Bernard, R. M., Bures, E. M., Borokhovski, E., \& Tamim, R. M. (2011). Interaction in distance education and online learning: Using evidence and theory to improve practice. Journal of Computing in Higher Education, 23(2-3), 82-103. doi:10.1007/s12528-011-9043-x

Anderson, T. (2003). Modes of interaction in distance education: Recent developments and research questions. In M. G. Moore \& W. G. Anderson (Eds.), Handbook of distance education (pp. 129-144). Mahwah, NJ: Lawrence Erlbaum Associates Inc.

Asterhan, C. S., \& Schwarz, B. B. (2007). The effects of monological and dialogical argumentation on concept learning in evolutionary theory. Journal of Educational Psychology, 99(3), 626-639. doi:10.1037/0022-0663.99.3.626

Baker, D. L. (2011). Designing and orchestrating online discussions. Journal of Online Learning and Teaching, 7(3), 401-411.

Bali, M., \& Ramadan, A. R. (2007). Using rubrics and content analysis for evaluating online discussion: A case study from an environmental course. Journal of Asynchronous Learning Networks, 11(4), 19-33.

Banna, J., Lin, M.-F. G., Stewart, M., \& Fialkowski, M. K. (2015). Interaction matters: Strategies to promote engaged learning in an online introductory nutrition course. Journal of Online Learning and Teaching, 11(2), 249-261.

Beck, V. S. (2010). Comparing online and face-to-face teaching and learning. Journal on Excellence in College Teaching, 21(3), 95-108.

Bernard, R. M., Abrami, P. C., Borokhovski, E., Wade, C. A., Tamim, R. M., Surkes, M. A., \& Bethel, E. C. (2009). A meta-analysis of three types of interaction treatments in distance education. Review of Educational Research, 79(3), 1243-1289. doi:10.3102/0034654309333844

Blumenfeld, P. C., Soloway, E., Marx, R. W., Krajcik, J. S., Guzdial, M., \& Palincsar, A. (1991). Motivating project-based learning: Sustaining the doing, supporting the learning. Educational Psychologist, 26(3-4), 369-398.

Britt, M. (2015). How to better engage online students with online strategies. College Student Journal, 49(3), 399-404.

Bolliger, D. U., \& Martindale, T. (2004). Key factors influencing student satisfaction with online courses. International Journal on E-Learning, 3(1), 61-67.

Chickering, A. W., \& Gamson, Z. F. (1987). Seven principles for good practice in undergraduate education. AAHE Bulletin, 39(7), 3-7.

Cuthrell, K., \& Lyon, A. (2007). Instructional strategies: What do online students prefer? Journal of Online Learning and Teaching, 3(4), 357-362.

Dixson, M. D. (2010). Creating effective student engagement in online courses: What do students find engaging? Journal of the Scholarship of Teaching and Learning, 10(2), 113. 
Student Perceptions on the Importance of Engagement Strategies in the Online Learning Environment

Everson, M., Gundlach, E., \& Miller, J. (2013). Social media and the introductory statistics course. Computers in Human Behavior, 29(5), A69-A81. doi:10.1016/j.chb.2012.12.033

Felder, R. M., \& Brent, R. (1996). Navigating the bumpy road to student-centered instruction. College Teaching, 44(2), 43-47.

Flick, U. (2006). An introduction to qualitative research (3rd ed.). Thousand Oaks, CA: Sage.

Gašević, D., Adesope, O., Joksimović, S., \& Kovanović, V. (2015). Externally-facilitated regulation scaffolding and role assignment to develop cognitive presence in asynchronous online discussions. The Internet and Higher Education, 24, 53-65. doi:10.1016/j.iheduc.2014.09.006

Garrison, D. R., \& Cleveland-Innes, M. (2005). Facilitating cognitive presence in online learning: Interaction is not enough. American Journal of Distance Education, 19(3), 133148. doi:10.1207/s15389286ajde1903_2

Gayton, J., \& McEwen, B. C. (2007). Effective online instructional and assessment strategies. American Journal of Distance Education, 21(3), 117-132. doi:10.1080/08923640701341653

Gilbert, P. K., \& Dabbagh, N. (2005). How to structure online discussions for meaningful discourse: A case study. British Journal of Educational Technology, 36(1), 5-18. doi:10.1111/j.1467-8535.2005.00434.x

Harrell, I. (2008). Increasing the success of online students. Inquiry: The Journal of the Virginia Community Colleges, 13(1), 36-44.

King, S. B. (2014). Graduate student perceptions of the use of online course tools to support engagement. International Journal for the Scholarship of Teaching and Learning, 8(1). doi:10.20429/ijsotl.2014.080105

Ko, S., \& Rossen, S. (2010). Teaching online: A practical guide (3rd ed.). New York: Routledge.

Lear, J. L., Ansorge, C., \& Steckelberg, A. (2010). Interactivity/community process model for the online education environment. Journal of Online Learning and Teaching, 6(1), 7177.

Lowyck, J., \& Pöysä, J. (2001). Design of collaborative learning environments. Computers in Human Behavior, 17(5-6), 507-516. doi:10.1016/S0747-5632(01)00017-6

Martin, F., \& Ertzberger, J. (2016). Effects of reflection type in the here and now mobile learning environment. British Journal of Educational Technology, 47(5), 932-944. doi:10.1111/bjet.12327

Meyer, K. A. (2014). Student engagement in online learning: What works and why. $A S H E$ Higher Education Report, 40(6), 1-114. doi:10.1002/aehe.20018

Moore, M. J. (1993). Three types of interaction. In K. Harry, M. John, \& D. Keegan (Eds.), Distance education theory (pp. 19-24). New York: Routledge.

Newmann, F. M., Wehlage, G. G., \& Lamborn, S. D. (1992). The significance and sources of student engagement. In F. Newmann (Ed.), Student engagement and achievement in American secondary schools (pp. 11-39). New York, NY: Teachers College Press. 
Student Perceptions on the Importance of Engagement Strategies in the Online Learning Environment

Nicholson, S. (2002). Socializing in the "virtual hallway": Instant messaging in the asynchronous web-based distance education classroom. The Internet and Higher Education, 5(4), 363372. doi:10.1016/S1096-7516(02)00127-6

Parker, M., \& Martin, F. (2010). Using virtual classrooms: Student perceptions of features and characteristics in an online and a blended course. Journal of Online Learning and Teaching, 6(1), 135-147.

Reushle, S., \& Mitchell, M. (2009). Sharing the journey of facilitator and learner: Online pedagogy in practice. Journal of Learning Design, 3(1), 11-20.

Revere, L., \& Kovach, J. V. (2011). Online technologies for engaged learning: A meaningful synthesis for educators. The Quarterly Review of Distance Education, 12(2), 113-124.

Richards, L. (2009). Handling qualitative data: A practical guide (2nd ed.). Thousand Oaks, CA: Sage.

Robinson, C. C., \& Hullinger, H. (2008). New benchmarks in higher education: Student engagement in online learning. Journal of Education for Business, 84(2), 101-108. doi:10.3200/joeb.84.2.101-109

Roblyer, M. D., \& Ekhaml, L. (2000). How interactive are YOUR distance courses? A rubric for assessing interaction in distance learning. Online Journal of Distance Learning Administration, 3(2). Retrieved from http://www.westga.edu/ distance/ojdla/summer32/roblyer32.html

Shea, P., Fredericksen, E., Pickett, A., Pelz, W., \& Swan, K. (2001). Measures of learning effectiveness in the SUNY Learning Network. Online Education, 2, 31-54.

Stavredes, T., \& Herder, T. (2014). A guide to online course design: Strategies for student success. San Francisco, CA: John Wiley \& Sons.

Tess, P. A. (2013). The role of social media in higher education classes (real and virtual) - A literature review. Computers in Human Behavior, 29(5), A60-A68. doi:10.1016/j.chb.2012.12.032

Ward, M. E., Peters, G., \& Shelley, K. (2010). Student and faculty perceptions of the quality of online learning experiences. International Review of Research in Open and Distance Learning, 11(3), 57-77.

Watkins, R. (2014). Developing e-learning activities. Distance Learning, 11(4), 62-64. 